\title{
Violation On the Basic Design of Al-Baghdadi City
}

\author{
Maan Mohie Mohammd Shareef \\ General Directorate of Education in Anbar, Iraq \\ dr.maan2019@gmail.com
}

\begin{abstract}
KEYWORDS: $\quad$ Basic Design, Violation, Qualitative, Quantitative, Negative Impacts.
\end{abstract}
Crossref doi https://doi.org/10.51345/.v32i4.420.g242

\begin{abstract}
:
The sustainable increasing in population coincided with continuous, constructional expansion of cites. It was the beginning of appearing the unlawful seizing of many areas in second world cities and the Iraqi cities in particular. thus it was very difficult for the mentioned cities to stand in front of these problems Al-Baghdadi city is also with in those cities that suffers from the illegal takings of many lands. The study aims to look over these unlawful misappropriating and to find out the reasons which stand behind this case and its locative distribution. The searcher depends on fielding study in checking these problem, through looking for many illegal taking which are not registered in Al-Baghdadi municipal. This study consists of three chapters, the first one is to know the meaning of misappropriating and its causes. The second chapter deals with the qualitative and locative circulation of these illegal behaviors and its affection on the constructional shape of the cites. While the third chapter considers the negative effects of this problem on the towns. This study gives many maps show these unlawful seizing in all districts in addition it gives the final conclusions and recommendation for this problem. Hopefully this study might be approved by all officials and members of governmental people. The study revealed that the abuses appeared clearly after 2007 due to the lack of security, the absence of the law and the difficulty of implementing it with the weakness of the regulatory bodies and the flexibility of some laws that gave the transgressor the right to own property as a reality that led to the exacerbation of the situation of abuses on the water, electricity, health and education services, as well as the abuses on land and streets and green areas.
\end{abstract}


التجاوزات على التصميم الأساس لمدينة البغدادي

\author{
م.د. معن محي محمد شريف \\ المديرية العامة لتربية الأنبار، العراق \\ dr.maan2019@gmail.com
}

الكلمات المفتاحية التصميم الأساسي، التجاوز، النوعي، الكمي، الاثار السلبية.

Crossref doi https://doi.org/10.51345/.v32i4.420.g242

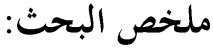

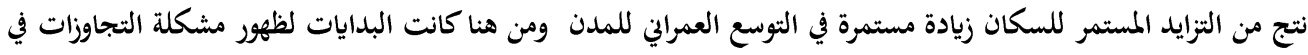

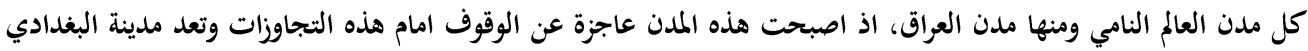

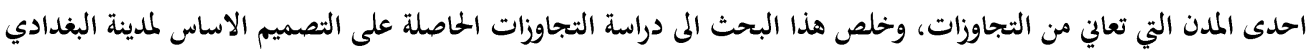

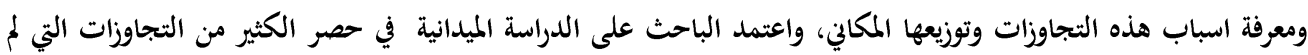

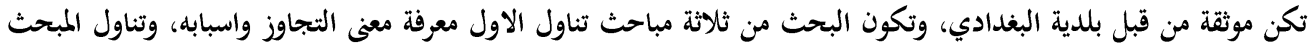

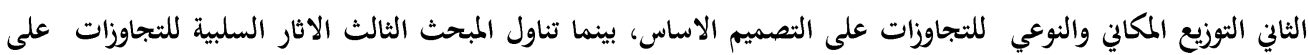

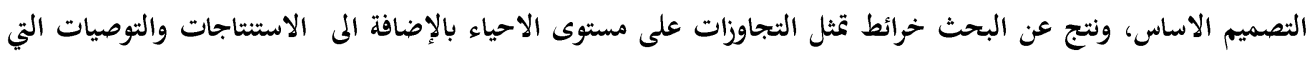

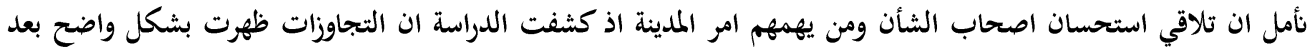

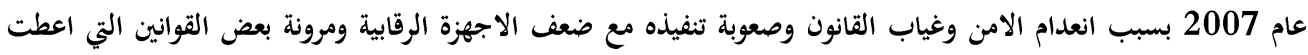

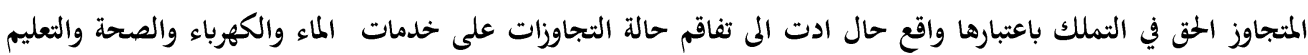
فضلا عن التجاوزات على الأراضي والشوارع والمناطق الحضراء.

المقدمة:

تعاني اغلب المدن العراقية ومنها مدينة البغدادي العديد من المشاكل التي واكبت النمو السكاني وتطور الججتمع الحضري، ومن أكثر المشاكل التي برزت وبشكل ملفت للنظر لاسيما بعد الاحتلال الامريكي للعراق عام 2003 الا وهي مشكلة التجاوزات على التصاميم الاساسية للمدن، اذ رافق الاحتلال تدهور للوضع الامني والاداري. اخذت هذه المشاكل تتفاقم سنة بعد اخرى كلما وجدت الظروف المناسبة لها

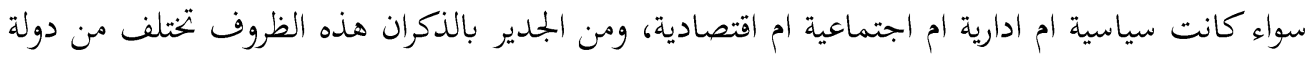

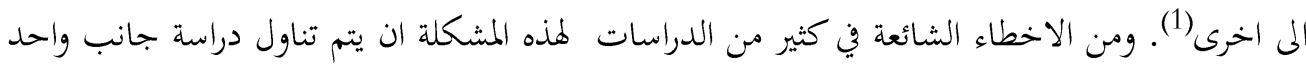


فقط دون الاخذ بنظر الاعتبار الجوانب الاخرى(2). ومن منطلق الشعور بالمسؤولية كون الباحث احد ابناء

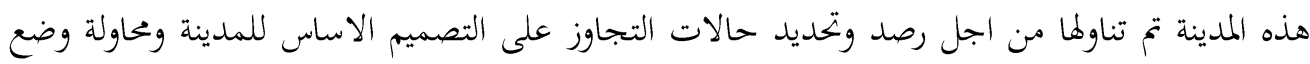
الحلول المناسبة التي نراها مناسبة للحد من هذه المشكلة. مشكلة البحث:

1- هل هنالك تجاوزات على التصميم الاساس لمدينة البغدادي؟

2- هل تتباين التجاوزات في انوعها وتوزيعها المكاني بين احياء مدينة البغدادي؟ همئه فرضية البحث: من خلال دراسة المنطقة تبين هنالك بتحاوزات على التصميم الاساس لمدينة البغدادي وتختلف هذه التجاوزات من حيث انواعها وتوزيعها المكاني بين احياء المدينة. هدف البحث: يهدف البحث الى معرفة اسباب التجاوزات وتحديدها ومعرفة انواعها وايجاد الحلول المناسبة للحد منها. حدود البحث: تمثلت حدود البحث بالحدود المكانية والتي تشمل حدود التصميم الاساس لمدينة البغدادي

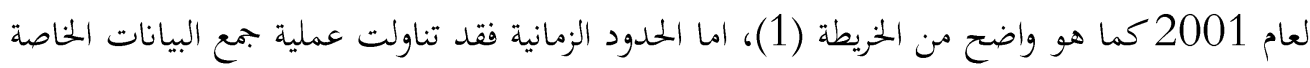
بالبحث لعام 2019.

خريطة (1) موقع مدينة البغدادي من محافظة الأنبار

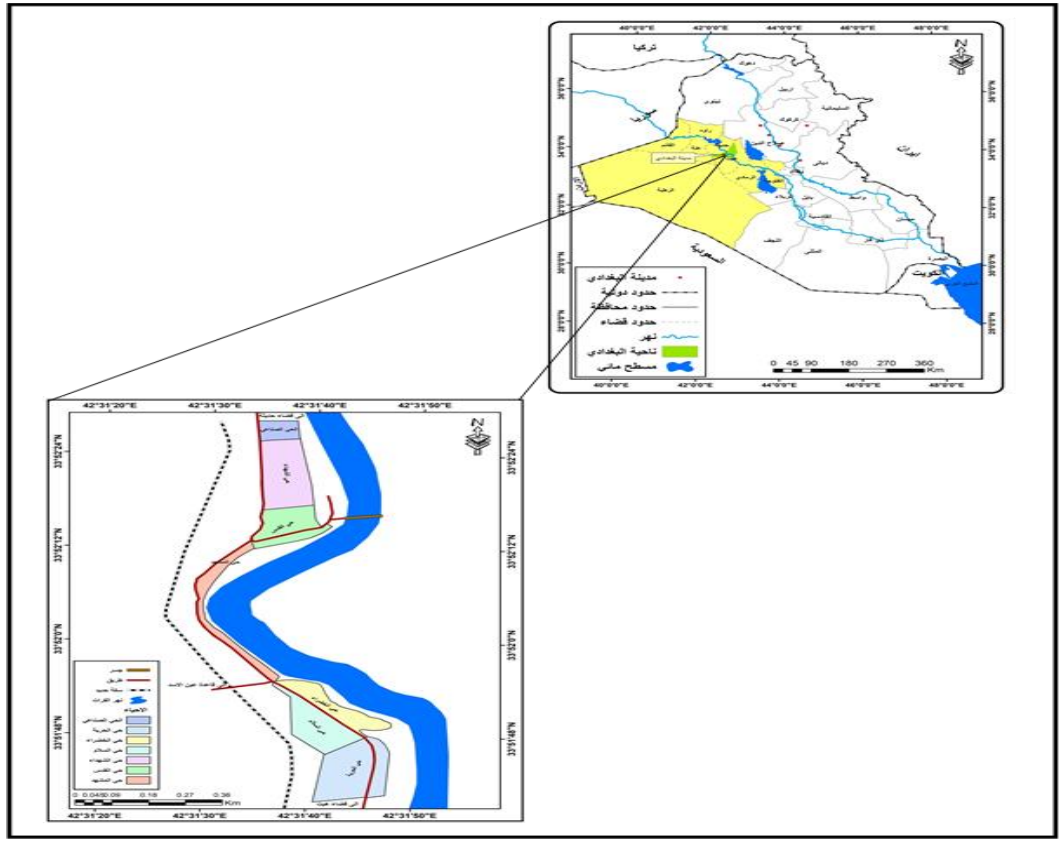

المصدر : جمهورية العراق، وزارة الموارد المائية، مديرية المساحة العامة، خريطة محافظة الانبار الادارية، لسنة 2000. 
المبحث الاول: التجاوز واسبابه: - المبا:

\section{(اولاً: التجاوز: (n)}

التجاوز يعني في اللغة بتاوز المكان اي تعداه وتخطاه وتخطا الحدود المسموح بها(4)، ومصطلح التجاوز تغيير صنف استعمالات الارض بواسطة شخص أو مؤسسة دولة على اراضي معينة من خلال السيطرة عليها بدون قانون(5)، والتجاوز هو ما يقوم به فرد او افراد او هيئات رسمية او غير رسمية من تغير في بنية المدينة

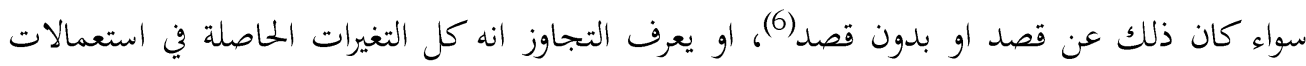
الارض ضمن التصميم الاساس من قبل الافراد بشكل غير قانوين (7).

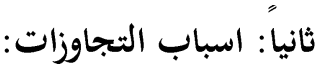

تختلف اسباب التجاوزات من مدينة الى اخرى وفقا المى مجموعة متغيرات سواء كانت (سياسية، اقتصادية،

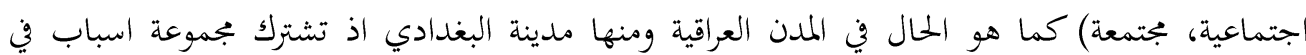
حدوث هذه التجاوزات على التصاميم الاساسية ويمكن ايماز هذه الاسباب بما يلي:

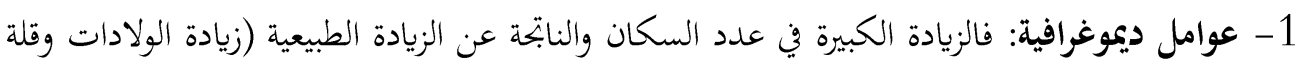
الوفيات) فضلا عن عامل الهجرة من القرى والمناطق التي حدثت فيها عمليات عسكرية ساهم في زيادة سكان المدينة.

2- عامل الموضع: كان لموضع مدينة البغدادي بين الضفة اليمنى لنهر الفرات وحافة الهضبة الغربية الاثر

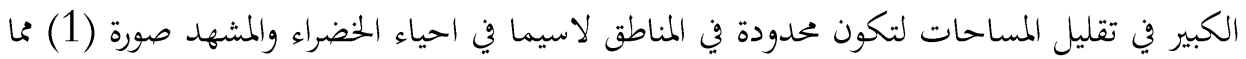
استوجب الزحف على مناطق اخرى.

صورة (1) تأثير الموضع على التوسع العمراني لمدينة البغدادي

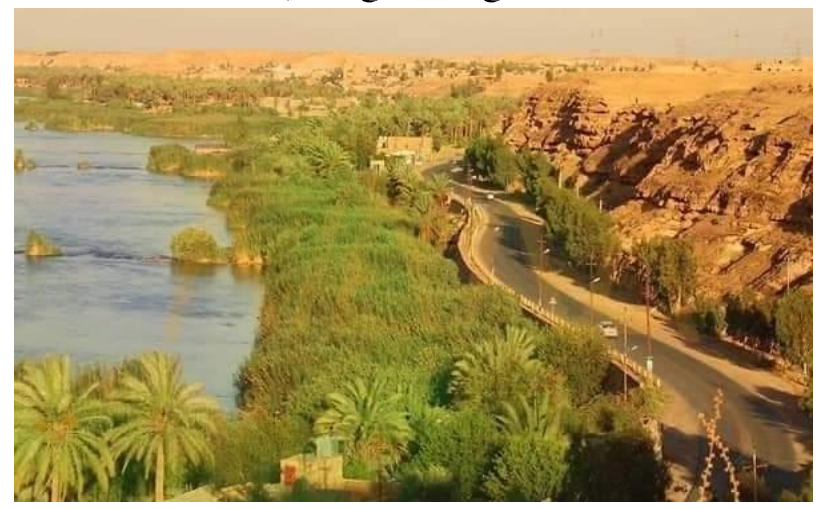

2019/9/15 التقطت الصورة بتأريخ 
3- عوامل اجتماعية (كالطالعة) وهو عرف عشائري متعارف عليه بان الاراضي التي تقع في هاية الاراضي الطابو تعد ملك لهذه العشيرة او الفرد بدون وجود سند قانوني لذلك، وكذلك شعور السكان بان السكن بالقرب من اقاركم بدون الاخذ بنظر الاعتبار عن كون هذه الارض متجاوز عليها ام لا، فضلا عن اطماع الكثير من اصحاب الاموال في شراء اراضي متجاوز عليها وبأسعر

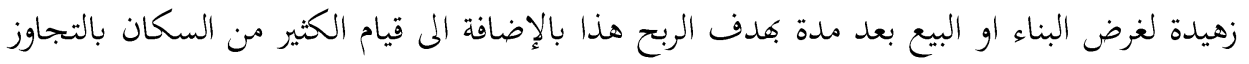
على الشوارع او الحدائق العامة ببناء سياج للمنزل او استغلالما حديقة خاصة مما ادى اتباع بقية الساكنين معه نفس الطريقة وهذا ادى الى تزايد هذه الحالات(8). 4- عوامل اقتصادية: وتتمثل بانخفاض المستوى المعاشي للكثير من سكان المنطقة وارتفاع نسبة البطالة وارتفاع اسعار الاراضي ذات السندات القانونية وارتفاع معدل الايجارات ادى هذا كله الى بتحاوز المواطنين على الكثير من الاراضي لاسيما السكنية.

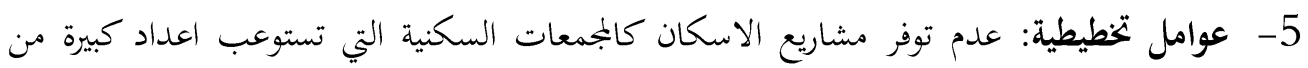
السكان وتقلل من نسبة العجز السكني وعدم قيام بلدية البغدادي بتوزيع الاراضي السكنية للمواطنين ممن لمم استحقاق فيها و ضعف الاجهزة الرقابية المتمثلة بالبلدية وعدم وجود موقف حازم للمسؤولين من خلال محاسبة بعض ضعاف النفوس مع المتجاوزين، فضلا عن صدور قوانين وتشريعات تعمل على تمليك المتجاوزين بعد تغريكمم بغرامات رمزية شجع المواطنين على التجاوز، ومما يجدر القول ان عدم تنفيذ الكثير من فقرات المخطط الاساس بشكل كامل وبوقت مناسب ترك مساحات فارغة سهلت عملية التجاوز عليها وهذا ما وجده الباحث من الدراسة الميدانية فيتجاوز المواطنين على مئى الكثير من المناطق الخضراء والحي الصناعي بشكل كامل. 6- عوامل سياسية وامنية: يعد ضعف تطبيق القانون أحد اهم اسباب التجاوزات على التصميم

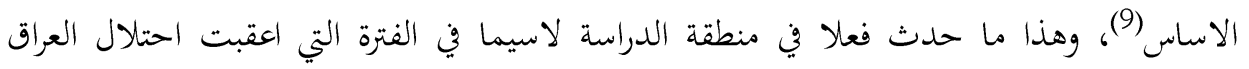
وتحديدا عام 2007 اذ حدث التجاوز فيها بشكل كبير بسبب تدهور الوضع الامني وغياب سلطة القانون فضلا عن الفساد الاداري، فشملت التجاوزات مناطق مختلفة أدت الى ظهور العشوائيات ووضع اليد على مباني الدولة من قبل المتجاوزين وكذلك التجاوز على الشوارع والارصفة وانتشار المحلات والورش الصناعية داخل الاحياء السكنية(10). 
المبحث الثاني: التوزيع النوعي والمكاني للتجاوزات على التصميم الاساس لمدينة البغدادي.

\section{اولاً: التوزيع النوعي للتجاوزات على التصميم الاساس لمدينة البغدادي:}

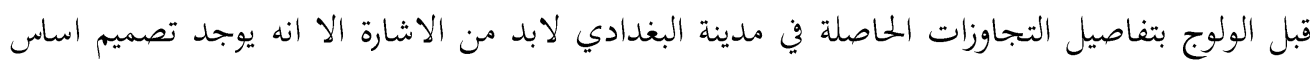
واحد للمدينة الذي اقر عام 1973 والذي يتكون من حيين فقط تسمى بالبغدادي الشرقية (حي الخضراء

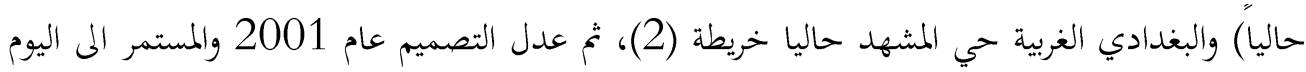

خريطة (2) مدينة البغدادي بموجب تصميم عام 1973

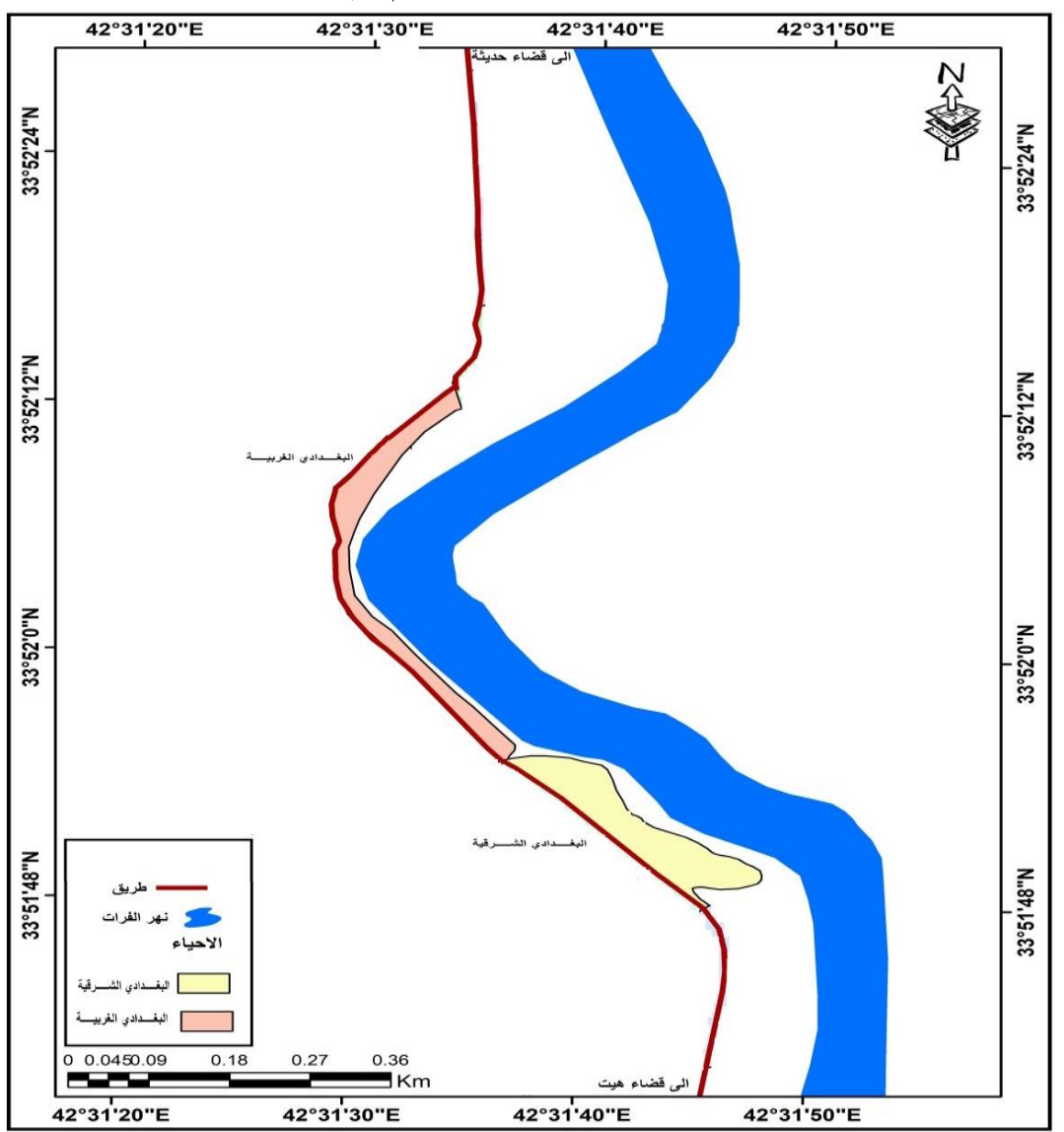

المصدر : دائرة بلدية البغدادي، قسم تخطيط المدن.

ومن الدراسة الميدانية خريطة (3) تبين انه لا توجد اي بحاوزات مثبته لدى بلدية البغدادي قبل الاحتلال الامريكي، وتبين من المسح الميداني ان التجاوزات اخذت اشكال متعددة وكما يأتي: 
1- تجاوزات المواطنين بتغيير استعمالات الارض: تهدف التصاميم الاساسية للمدن الى تحقيق العدالة والرفاهية للسكان من خلال التوزيع العادل لاستعمالات الارض ويجب ان يكون هذا التصميم قابل للتطبيق وفيه من المرونة ان يستوعب التغيرات التي يمكن ان تطرأ على المدينة سواء كانت هذه التغيرات سلبية ام ايهابية، ومن الملاحظة الميدانية تبين ان اغلب البيوت المطلة على الشوارع الرئيسية

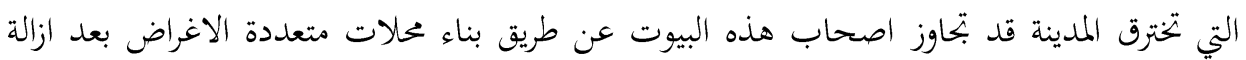
اسيجة المنازل

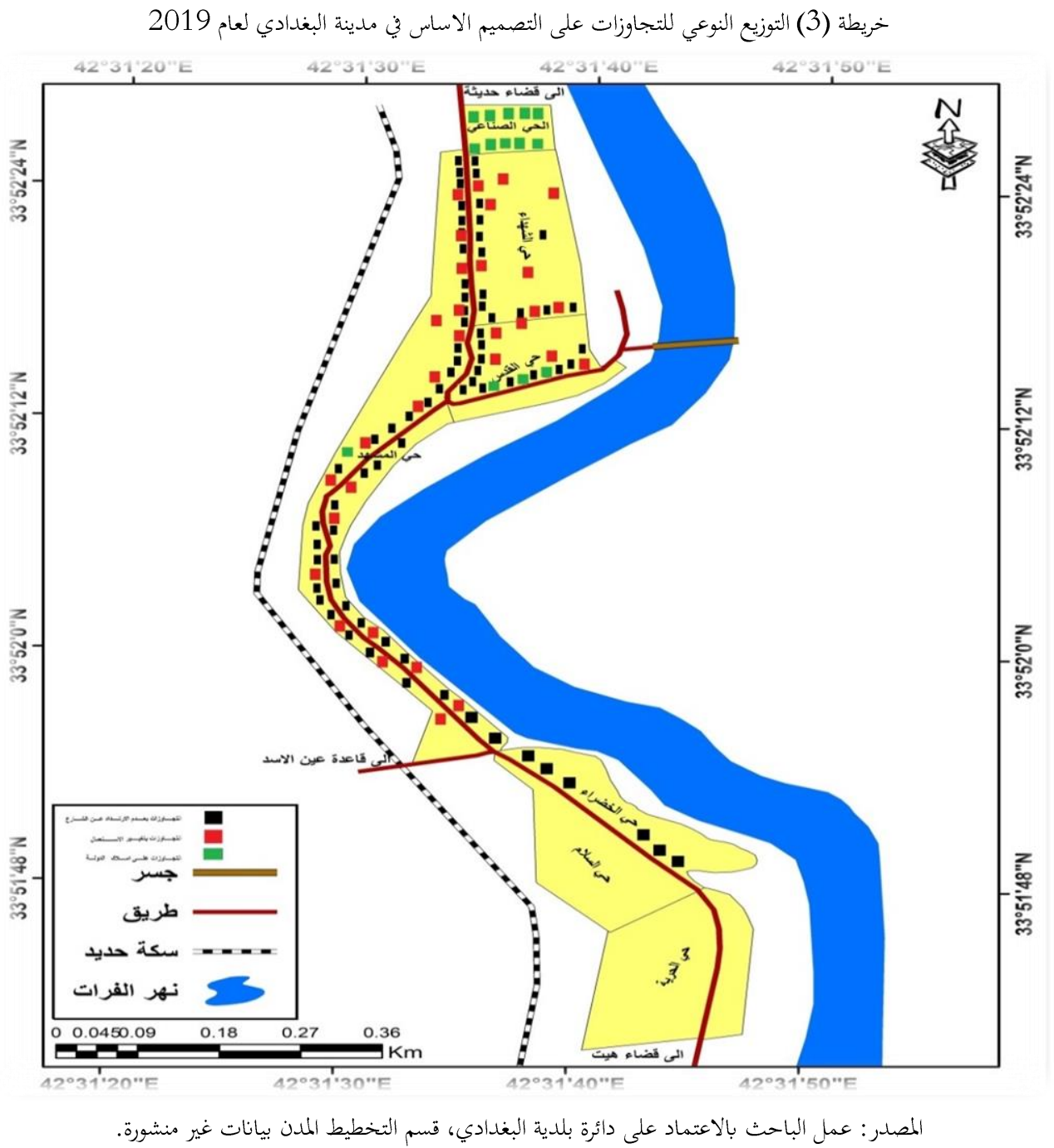


وتحويلها المى محلات غذائية وبقالة ومحلات تبديل دهن وبنجرجي ومحلات غسل سيارات وورش تصليح

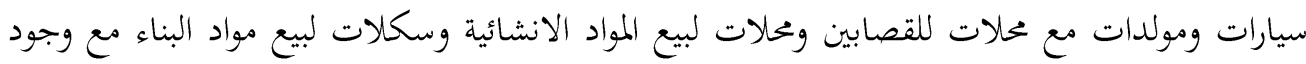
الصيدليات وعيادات الاطباء ومن الجلدير بالذكر ان هذه الاستعمالات تتغير من مواطن الى اخر حسب لهب رغبته او حسب الحاجة اليها فمثلا محل يمكن ان يستخدم كورشة تصليح او بيع ادوات احتياطية للسيارات

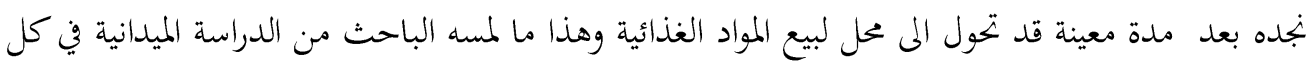

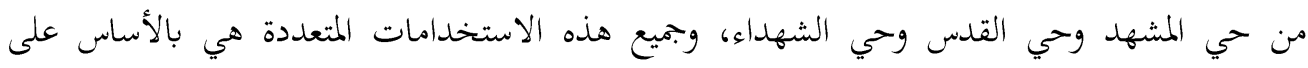
حساب راحة المواطن وهي تشويه للتصميم الاساس للمدينة. 2- تجاوزات المواطنين بعدم الارتداد عن الشارع: يمثل هذا النوع من التجاوزات التي يمارسها المواطنين

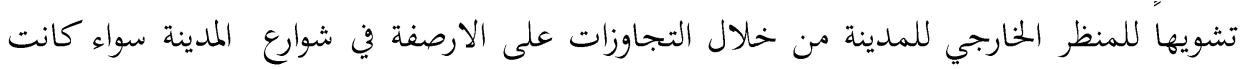

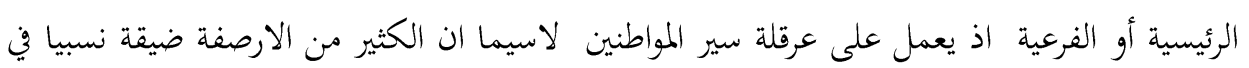

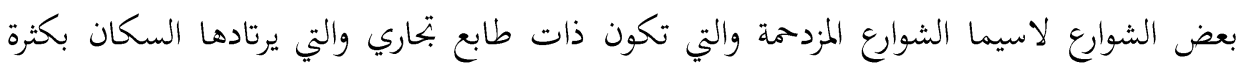

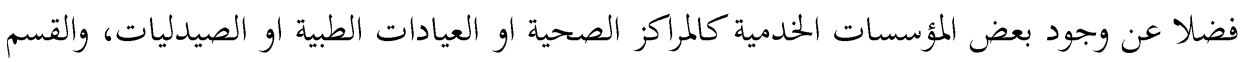
الاخر من الشوارع لا توجد ارصفة بل اكتاف ترابية للشوارع كما هو الحال في الشارع الرئيسي لمدينة البغدادي ومن الدراسة الميدانية يصل عرض الاكتاف في بعض المناطق (3-4) متر عن الشارع

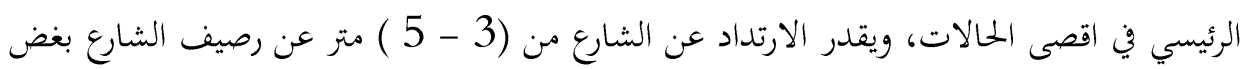

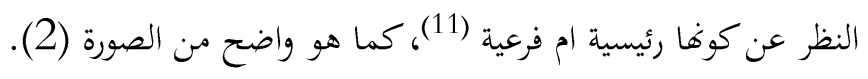
صورة (2) الشارع الرئيسي في حي المشهد والذي يمثل عدم وجود رصيف للشارع

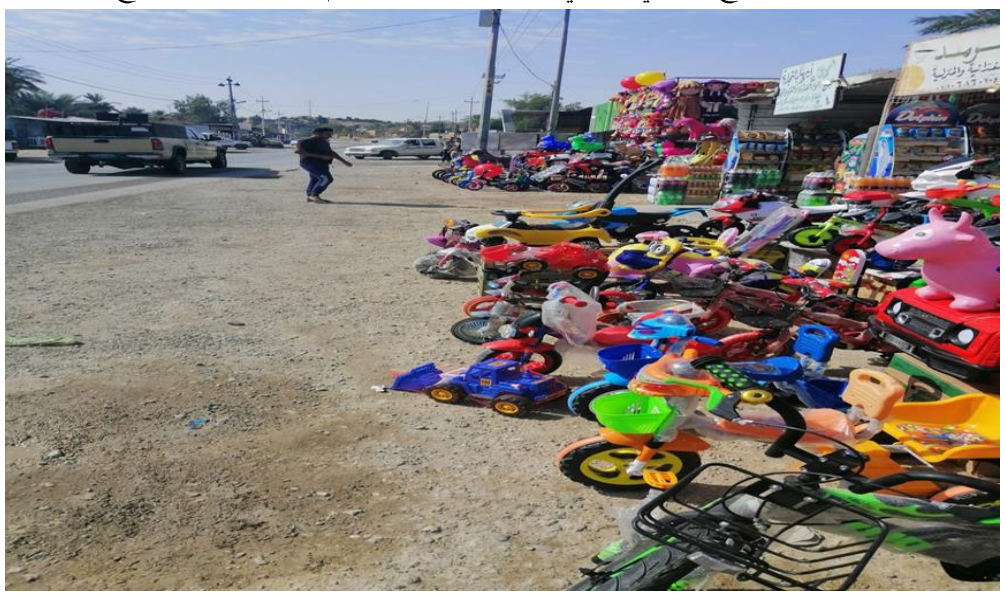

2019/9/17 التططت هذه الصورة بتاريخ 
ومن الدراسة الميدانية ان هذا النوع من التجاوز في منطقة الدراسة في الشوارع ذات الحكة التجارية اذ يعمل اصحاب كثير من المحلات عرض بضائعهم على الرصيف وقسم اخر يعمل على وضع سياج من الحديد

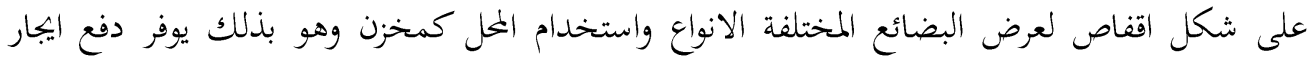
المخزن، ولابد من الاشارة هنا الى الكثير من اصحاب المحلات بإيقاف سياراقم على الارصفة واعتبارها موقف خاص بهم دون الاخذ بنظر الاعتبار ما تسبه الاسيجة الحديدة والسيارات والبضائع من اعاقة حركة المارة وتشويه منظر.

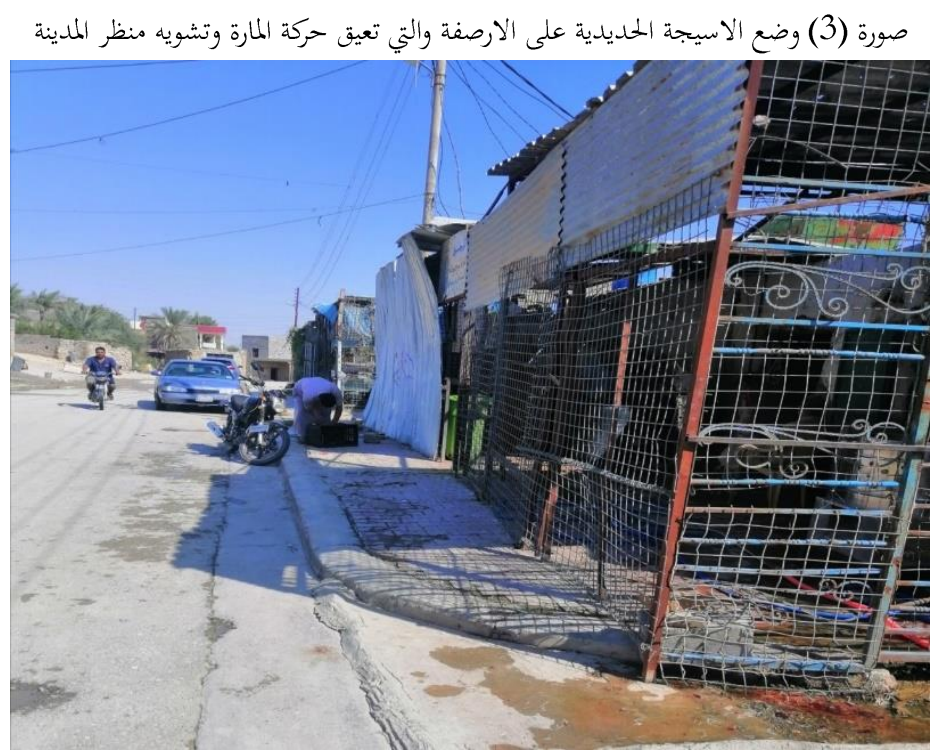

2019/9/20 التقطت الصورة بتأريخ

الشوارع، كذلك الحال توجد بعض التجاوزات على الارصفة من قبل مؤسسات الدولة بعدم الارتداد عن الشارع من خلال وضع حواجز اسمنتية امام بعض الدوائر في الشوارع الرئيسية او الفرعية لضرورات امنية كما هو الحال في الشارع الرئيسي في حي الشهداء وحي الخضراء. ومن خلال هذا الاستعراض لهذا النوع من التجاوز فلا بد قبل الشروع بتخطيط استعمالات الارض ان تسبقها دراسة معمقة من حيث اطوالها وعرضها وطاقتها الاستيعابية مع الاخذ بنظر الاعتبار تخصيص اماكن خاصة لوقوف السيارات لعدم التأثير على الحركة في هذه الشوارع(12). 3- التجاوزات على املاك الدولة: كان لتأخير تنفيذ بعض من مراحل التصميم الاساس اثر كبير في

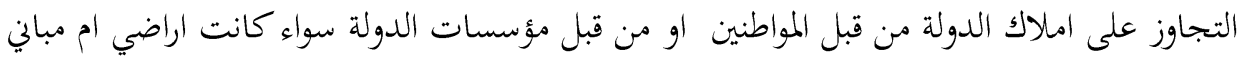


وهي خخططة لاستعمالات معينة، ومن الدراسة الميدانية تبن هنالك عدة امثلة على هذا النوع من التجاوز كاستخدام بناية كانت مقرا لحزب العث المنحل وتم استخدامها كبناية لمدرستان ابتدائيتان

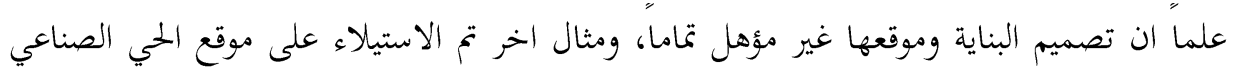

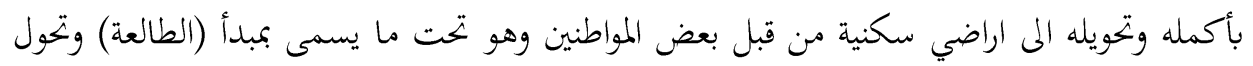

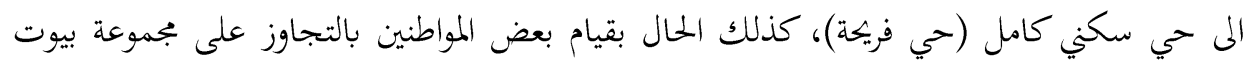

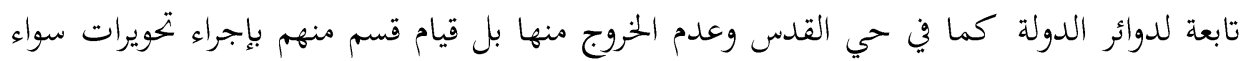
ببناء غرف او استغلال سطح المنزل ببناء طابق ثاني او بهدم الاسيجة وبناء محلات منها، ومما يلفت

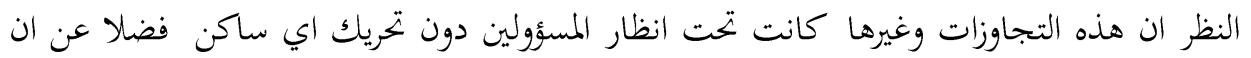

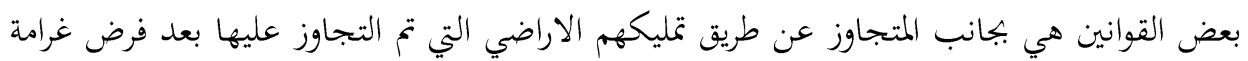

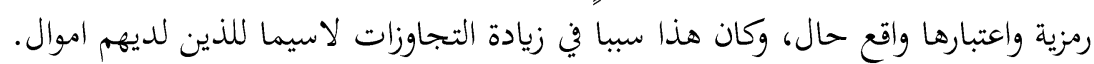

\section{ثانياً: التوزيع الكمي للتجاوزات على التصميم الاساس لمدينة البغدادي:}

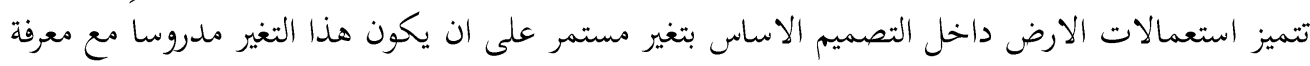

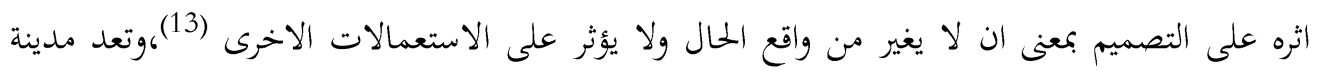

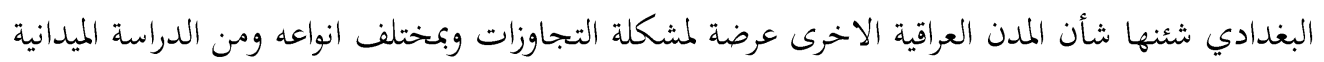
ان التجاوزات تختلف من حي الى اخر حسب مساحة الحي وفرص التجاوز المتاحة فيه من وجود مساحات

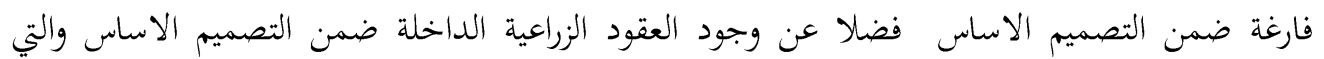
حولت اراضيها من قبل الاشخاص المتعاقدين الى قطع سكنية بيعت للمواطنين وبأسعار منخفضئ

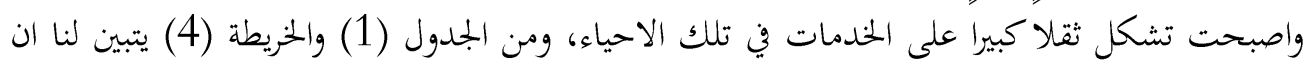
عدد التجاوزات بمختلف اشكالها بلغت (473) بحاوزا وموزعة حسب الاحياء كالاتي:

جدول (1) التوزيع المكاني للتجاوزات حسب الاحياء السكنية في مدينة البغدادي

\begin{tabular}{|c|c|c|c|}
\hline موقعها من التصميم & نوعها & عدات & 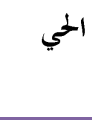 \\
\hline 15 اراضي فارغة /4شارع/3 مناطق خضراء & سكن & 22 & \multirow[t]{2}{*}{ الحرية } \\
\hline اراضي فارغة & محلات & 5 & \\
\hline اراضي خضراء & سكن & 12 & \multirow[t]{2}{*}{ السلام } \\
\hline 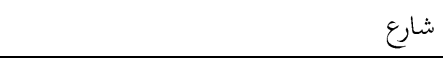 & سياج & 3 & \\
\hline
\end{tabular}




\begin{tabular}{|c|c|c|c|}
\hline 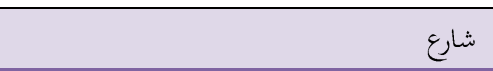 & محلات & 6 & \\
\hline 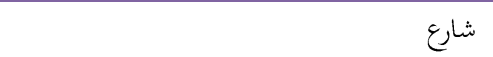 & محلات & 44 & \multirow[t]{2}{*}{ 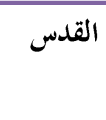 } \\
\hline خضراء & سكن & 15 & \\
\hline 80 شارع/ 5 اراضي خضراء/ 9 مباني عامة & محلات & 94 & \multirow[t]{3}{*}{ المشهد } \\
\hline 8سكنية /3 مباني عامة /2 اراضي فارغة & سكن & 13 & \\
\hline شارع & سياج & 13 & \\
\hline 7 مباني عامة/ 27 خضراء/13 فارغة & محلات & 47 & \multirow[t]{3}{*}{ 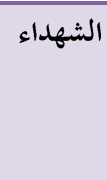 } \\
\hline 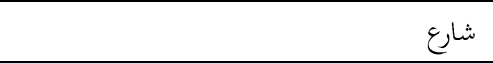 & سياج & 12 & \\
\hline 20 سكن / 16 مباني عامة / 2 اراضي خضراء & سكن & 38 & \\
\hline حي صناعي & سكن & 105 & \multirow[t]{3}{*}{ 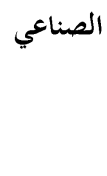 } \\
\hline حي صناعي & محلات & 7 & \\
\hline حي صناعي & ملeعب & 1 & \\
\hline \multirow[t]{2}{*}{ 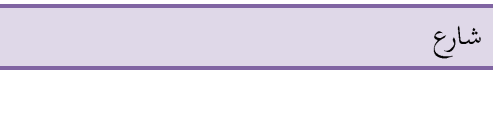 } & محلات & 36 & الخضراء \\
\hline & & 463 & الجموع \\
\hline
\end{tabular}

المصدر: عمل الباحث بالاعتماد على بلدية البغدادي، قسم تنظيم المدن، بيانات غير منشورة لعام 2019

خريطة (4) التجاوزات الكمية على التصميم الاساس لمدينة البغدادي لعام 2019

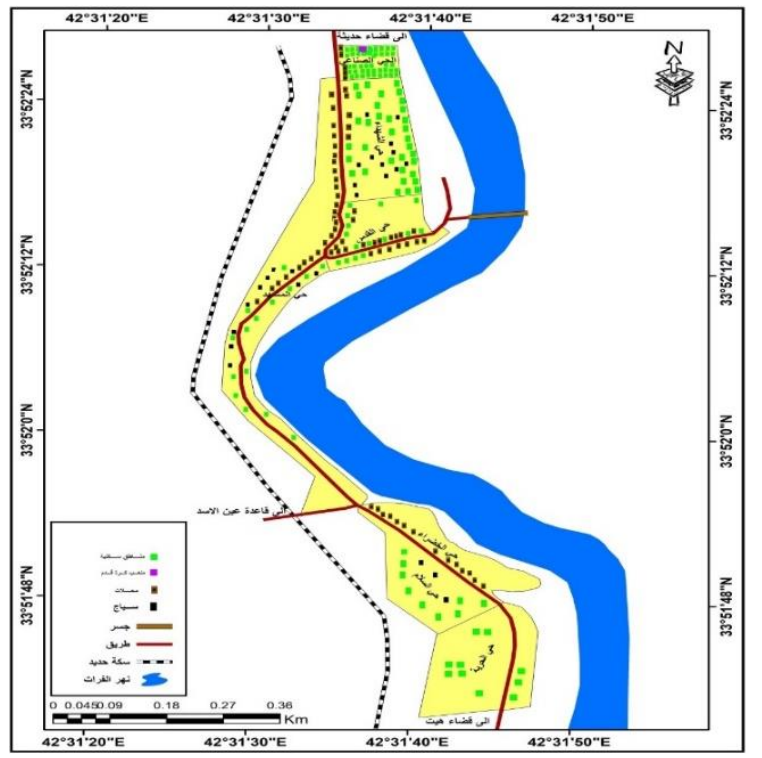

المصدر: عمل الباحث بالاعتماد على بلدية البغدادي، قسم تخطيط المدن بيانات غير منشورة. 
1- حي الحرية: يتضح من الجدول (1) والخريطة (3) ان عدد التجاوزات (27) تجاوزا سكنيا توزعت

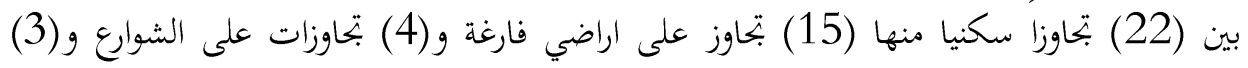
بحاوزات على المناطق خضراء، و(5) بحاوزات لمحلات على اراضي فارغة.

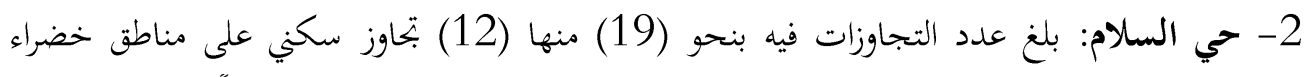

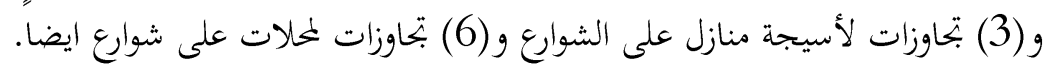

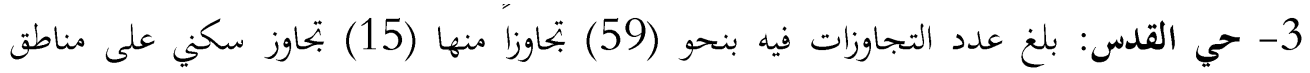

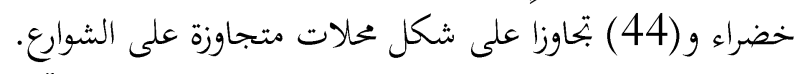

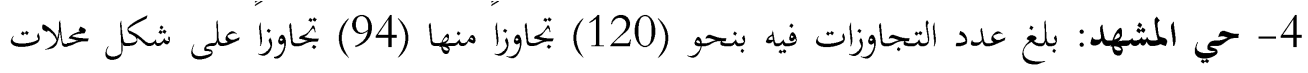

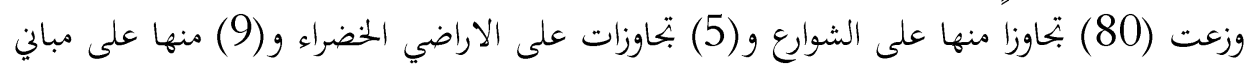

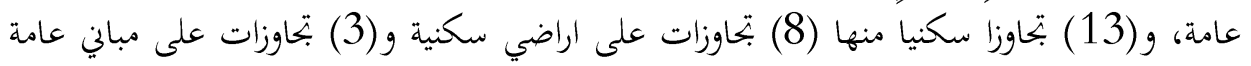
و(2) بتاوزاً على اراضي فارغة.

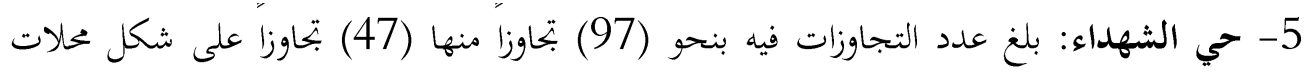

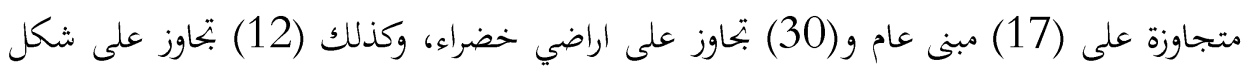

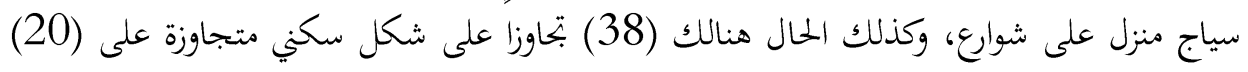
منطقة سكنية و(16) مباني عامة و(2) مناطق خضراء.

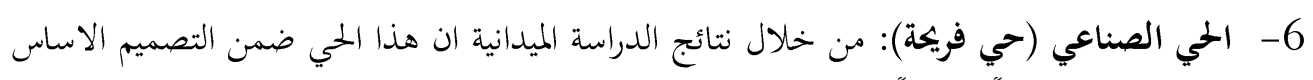

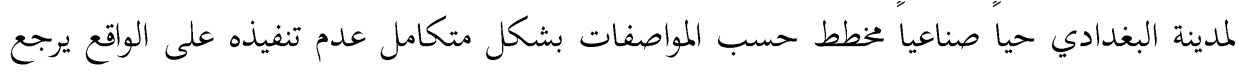

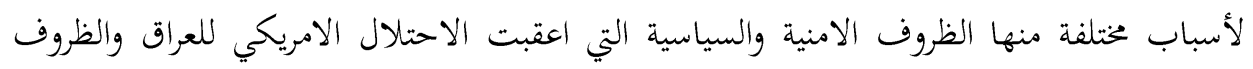

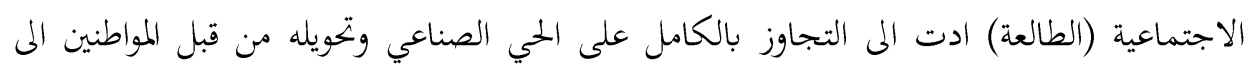

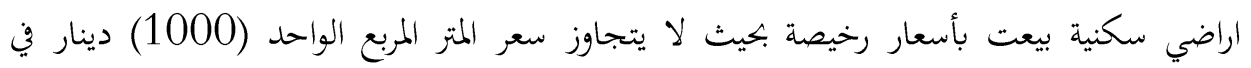

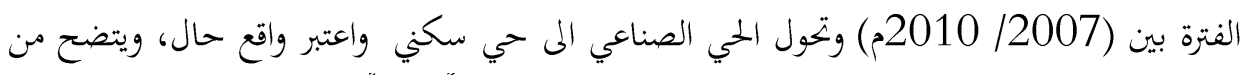

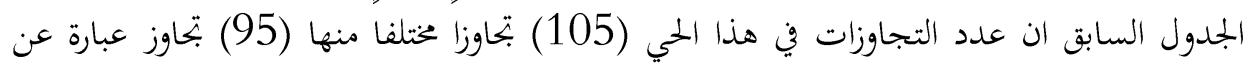
سكن و (10) محلات متعددة الاغراض وملعب واحد فماسي لكرة القدم.

المبحث الثالث: الاثار السلبية للتجاوزات على التصميم الأساس في مدينة البغدادي لعام 2019

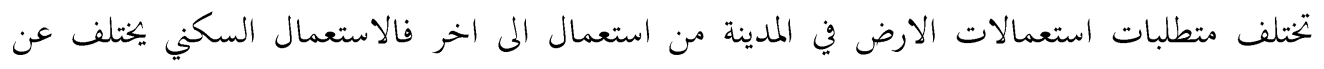

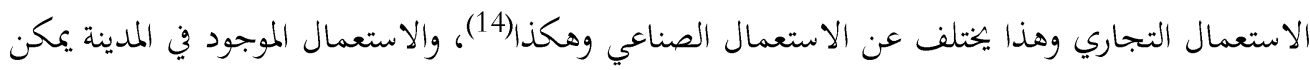


ان يصبح غير مجدي بعد فترة زمنية معينة الامر الذي يستوجب الانتقال الى موضع اخر يتحقق فيه النمو

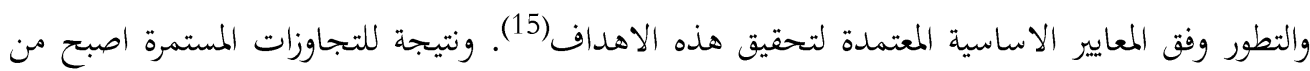

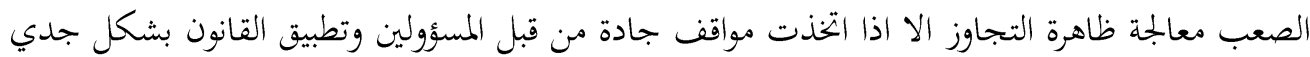
وغير انتقائي، ومن الاثار السلبية التي ظهرت من الدراسة الميدانية في مدينة البغدادي وهي كالاتي:

\section{أولا: الأثار الاقتصادية:}

1- تحول مساحات من البساتين الى مساكن وقسم اخر الى مطاعم بعد ازالة اشجار النخيل والحمضيات

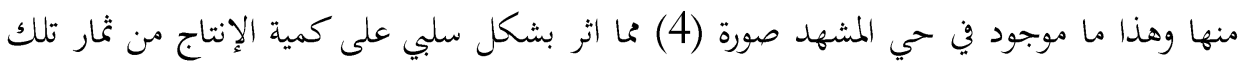
البساتين.

صورة (4) مطعم ظلال النخيل في البغدادي الذي شيد في أحد البساتين بعد قطع الاشجار

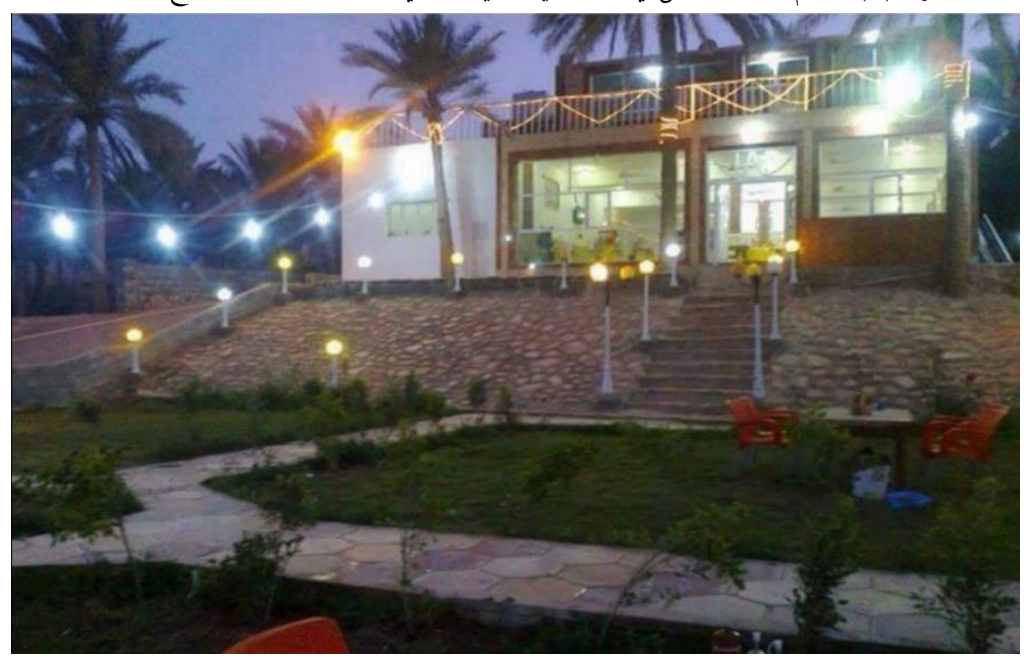

$$
\text { التقطت الصورة بتأريخ /9/24 } 2019
$$

2- انخفاض اسعار الكثير من الاراضي التي بيعت كأراضي متجاوز عليها علماً ان موقعها يحتم ان تكون بأسعار أكثر من ذلك لاسيما في التخطيطات المستقبلية.

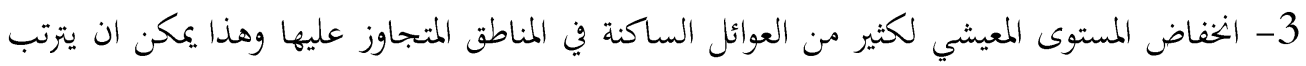
عليه مشاكل عند البعض في المستقبل. 
ثانيا: الاثار الثقافية والاجتماعية:

1- اختلاف المستوى الثقافي بين سكان مناطق التجاوز كوفم قدموا من مناطق مختلفة فضلا عن وجود فوارق في العادات والتقاليد بينهم الامر الذي رجح حدوث مشاكل في المستقبل القريب. 2- انتشار ظاهرة الترييف الحضري بين الاحياء داخل المدينة عن طريق قيام بعض العوائل بتربية الماشية

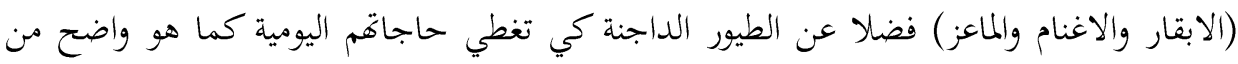

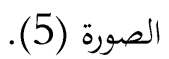

صورة (5) ظاهرة الترييف في مدينة البغدادي

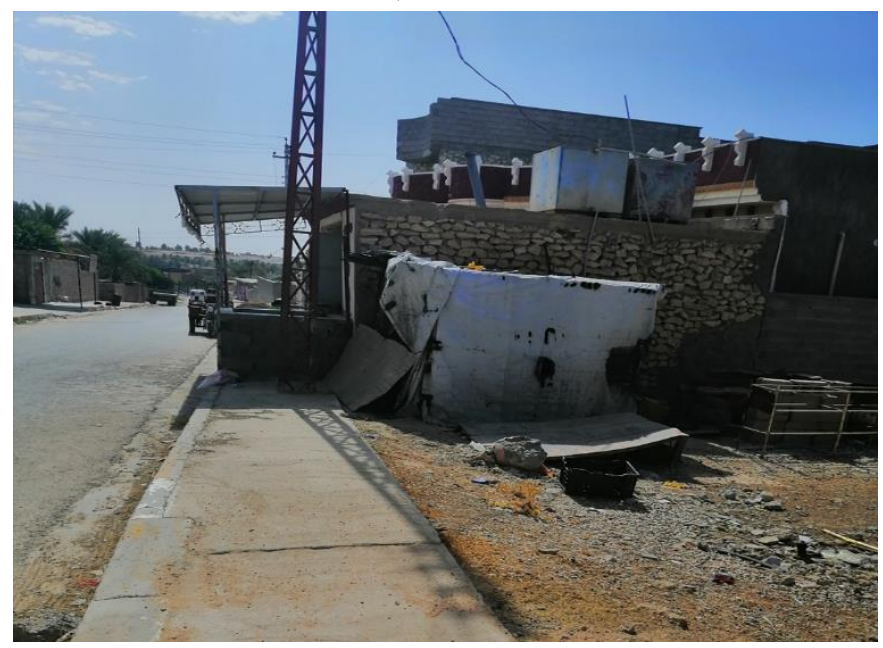

$2019 / 9 / 25$ التقطت الصورة بتأريخ

\section{ثالثاً: الاثار التخطيطية:}

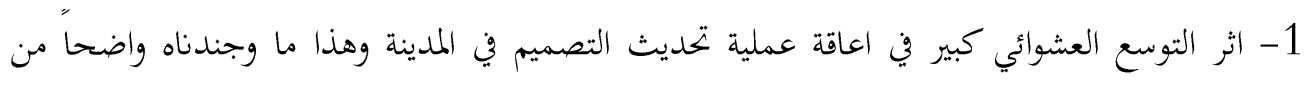

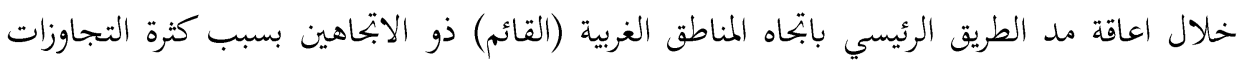
على الشارع واكتافه.

2- انتشار البناء الغير منتظم في كثير من الاحياء وعدم الارتداد عن الشارع ساهم في اعاقة تنفيذ الكثير من الشوارع او تضييقها كما هو حاصل في شارع القدس وفي الشارع الحولي وشارع دائرة الزراعة في النياء حي الشهداء. 


\section{رابعا: الاثار الحُمية:}

1- كان لمشكلة التجاوزات اثرا كبيرا على الحندمات وبمختلف انواعها اذ تعاني المدينة بصورة عامة من نقص كبير في التجهيز الكهربائي ومما زاد من هذه المعاناة وجود المتجاوزين وبأعداد كبيرة ادى الى حدوث ضغط كبير على الكهرباء.

2- معاناة سكان بعض الاحياء ومن ضمنهم المتجاوزين من شحة المياه لاسيما في فصل الصيف اذ تصل مدة انقطاع المياه من (3/2) أيام.

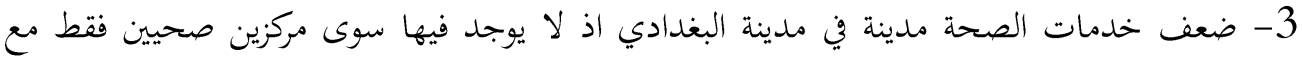

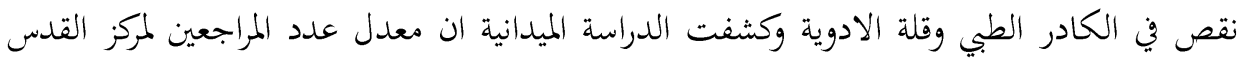
الصحي (890) مراجع شهرياً(16) وهذا ضغط كبير مقارنة بالخدمة التي يؤديها. 4- تعاني بعض المدارس لاسيما الابتدائية منها من ضغط كبير عليها بسبب زيادة اعداد التلاميذ وعند زيارة عدد منها لاسيما مدرسة عبد الرحمن بن عوف الابتدائية للبنين وابتدائية التسامح للبنات تبين هنالك عدد كبير من التلاميذ في بعض الصفوف يصل الى (47) تلميذ|(17) وهذا يفوق المعايير العراقية المعتمدة.

\section{خامسا: الاثار البيئية: - (1)}

1- انتشار النفايات المنزلية وبكميات كبيرة في المناطق السكنية وكما هو واضح في الصورة (6) مع عدم امكانية البلدية في تغطية جميع مناطق المدينة اصبحت تشكل عبئ كبير على المدينة لاسيما انتشار الروائح في مكبات النفايات واصبحت مناطق لتجمع الحشرات والحيوانات السائبة. 2- التلوث البصري والناتج عن عدم ترتيب واجهات المحلات والمباني من خلال استخدام السقائف

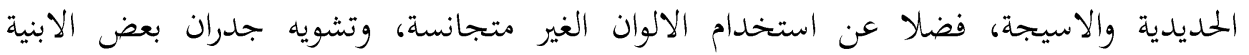
بالكتابات والدعايات وغيرها. 3- الضوضاء الناتجة من تشغيل المولدات الاهلية في هذه الاحياء وما تخلفه من غازات وعوادم تساهم في رفع نسبة التلوث. 


\section{صورة (6) تراكم النفايات في حي الشهداء مدينة البغدادي}

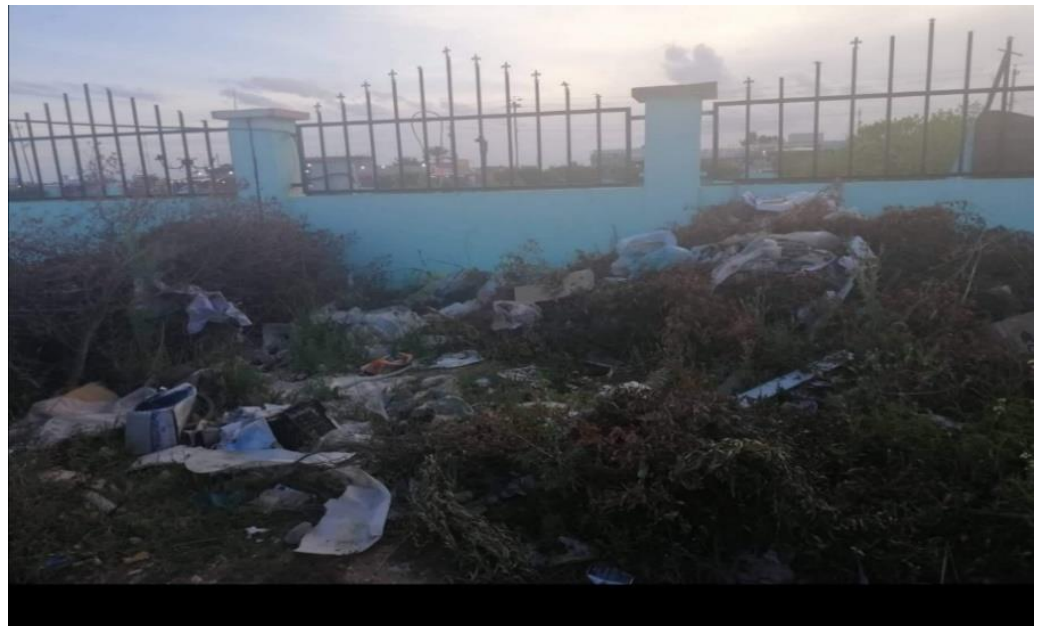

التقطت الصورة بتأريخ /9/25/

\section{سادسا: الآثار المورفولوجية:}

والنابحة عن انتشار البناء الغير منتظم للمساكن او للمحلات التجارية واستخدام الاسيجة الحديدية في المناطق المتجاوز عليها.

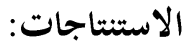

1- كشفت الدراسة ان التجاوزات ظهرت بشكل واضح بعد عام 2003 بسبب انعدام الامن وغياب القانون وصعوبة تنفيذه مع ضعف الاجهزة الرقابية ومرونة بعض القوانين التي اعطت المتجاوز الحق في التملك باعتبارها واقع حال ادت الى تفاقم حالة التجاوزات. 2- ولدت التجاوزات ضغطا كبيرا على الخدمات بمختلف انواعها كخدمات الكهرباء والماء والصحة والتعليه.

3- ان عدم توزيع الاراضي السكنية للمواطنين بالإضافة الى ارتفاع اسعار الاراضي دفعت الكثير من المواطنين الى التجاوز او شراء الاراضي المتجاوز عليها وهو يعلم بذلك. 4- شكلت التجاوزات على الشارع الرئيسي وشارع القدس وخاصة المحلات منظراً مشوها للمدينة كوها تفتقر الم ابسط مقومات الترتيب. 5- أصبح واضحا ان التجاوزات الكثيرة على المباني العامة وبصورة اوضح على المناطق الخضراء والتي يفترض ان تكون المتنفس للمدينة واماكن ترفيه للعوائل وللعب الاطفال. 
6- اختلاف الطابع الثقافي والعادات والتقاليد ما بين سكان المدينة ولاسيما المتجاوزين خلف الكثير

$$
\text { من المشاكل لم تكن معروفة في السابق }
$$

7- التلوث البصري والضوضاء التي احدثتها العشوائيات ولاسيما الترييف في المدن جعل من تلك

$$
\text { الاحياء ذات شكل غير لائق وهذا قلل طلب الشراء والسكن في تلك الاحياء. }
$$

1- على الجهات المختصة تنفيذ القوانين والقرارات الخاصة بالتجاوزات بصورة مباشرة والابتعاد عن

$$
\text { المجاملات والتأثيرات الشخصية. }
$$

2- ازالة كافة التجاوزات على الشارع الرئيسي وشارع القدس وإلزام الصحاب المحلات بأن تكون ترتيب ونسق السقائف موحد حتى يعطي جمالية للمدينة.

3- ازالة جميع التجاوزات بصورة فورية عن المناطق الخضراء والعمل على تنفيذ الغير متجاوز عليها

$$
\text { واعتبارها أولوية ضرورية. }
$$

4- العمل على اعادة ترتيب الورش الصناعية ومحلات خدمات السيارات عن طريق عزلها وتوحيدها في

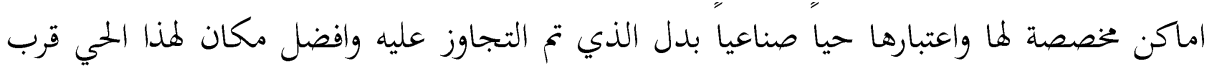
محطة الوقود لوجود مساحة فارغة ويمكن ان تبنى بطريقة (المساطحة) والذي يعني عمل عقد بين المواطن والدولة ببناء منشأ معين ويقوم المواطن باستغلاله لمدة (15) عاما ثم تعود ملكيته للدولة. 5- العمل على فرض غرامات مادية كبيرة لجميع التجاوزات من اجل الحدم منها.

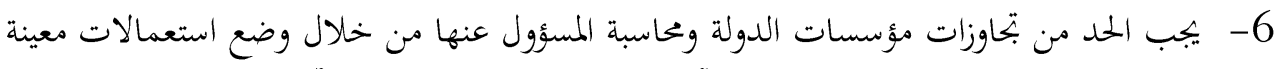
في أماكن غير مناسبة ليكون ذلك أنموذجا للمواطن بعدم التجاوز مستقبلاً. 7- يجب ان يكون هنالك تعاون بين البلدية والسكان من خلال إقامة لقاءات ومؤتمرات تثقيفية لتوعية السكان وبيان مدى أهمية الجانب التخطيطي للمدينة. 8- لاحقا اسوة بالمتجاوزين السابقين. 9- القيام بتطبيق جميع الفقرات المعدة في التصميم الأساس بما يتناسب مع الواقع من اجل تحقيق الأهداف المرجوة منه.

10-ضرورة انهاء مبدأ تمليك المتجاوزين وعدها واقع حال كونه يشجع على التجاوز املا في تمليكه 
لينا رشاد جلوب، التجاوزات على الاراضي المضرية واثرها على التطور العمراي في مدينة هيت،رسالة ماجستير غير منشورة، كلية التربية للبنات، جامعة

$$
\text { محمد ازهر سعيد السماك واخرون، اصول البحث العلمي، مطبعة جامعة صلاح الدين، الطبعة الثالثة، سنة } 1989 .
$$

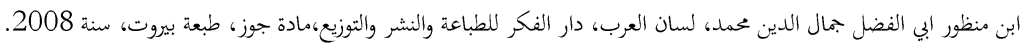

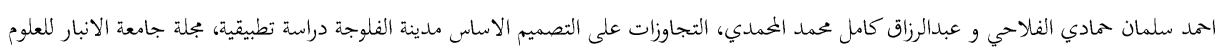

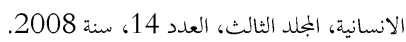

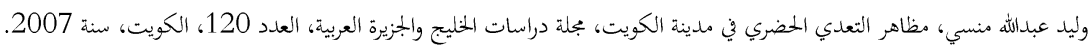

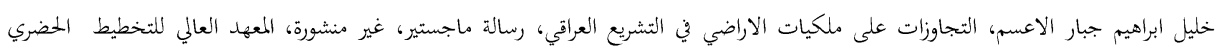

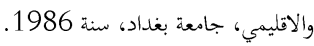

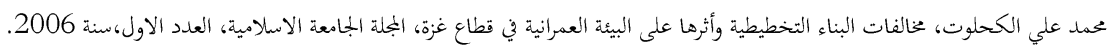

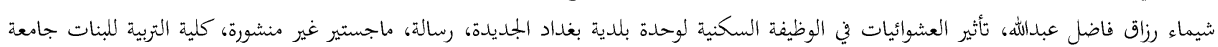
بغداد، سنة 2015. بشير ابراهيم الطيف واخرون، جغرافية المدن، جامعة بغداد، كلية التربية للعلوم الانسانية ابن رشد، قسم الجغرافية، دار الكتب والوثائق رقم 97، سنة 2017 علي ثائر طالب يوسف الزيدي، التجاوزات على التصميم الاساس لمدينة المالص، رسالة ماجستير غير منشورة، كلية التربية للعلوم الانسانية، جامعة ديالى، سنة 2017.

Gruen vector and smith brry, shopphing towns in U.S.A ,New York.1960.p 115 .12 عماد طارق عمر المديثي، التجاوزات الحاصلة على التصميم الاساس في مدينة تكريت، رسالة ماجستير غير منشورة نكلية التربية، جامعة تكريت، 2006 صلاح حميد الجنابي، التغيير في استعمالات الارض حول المدن العراقية، اطروحة دكتوراه، غير منشورة ن كلية الآداب، جامعة بغداد، سنة 1977.

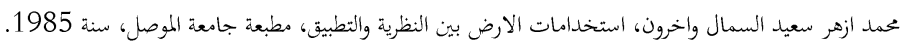
قطاع الرعاية الصحية في البغدادي، بيانات غير منشورة لعام 2019. .3 .4 .5

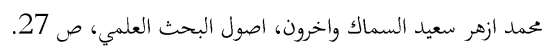

$$
\text { ابن منظور، لسان العرب، ص2111. }
$$

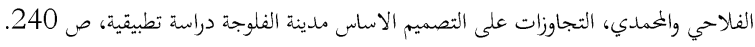

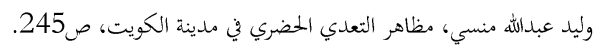

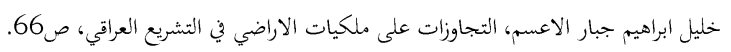

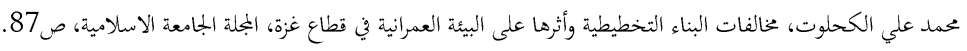

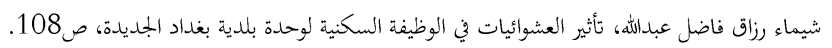

$$
\text { بشير ابراهيم الطيف واخرون، جغرافية المدن، ص268. }
$$

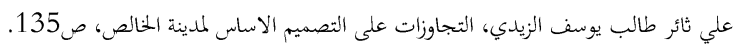

Gruen vector and smith brry, shopphing towns in U.S.A ,New York.1960.p 115

$$
\begin{aligned}
& \text { عماد طارق عمر الحديثي، التجاوزات الحاصلة على التصميم الاساس في مدينة تكريت، ص84. }
\end{aligned}
$$

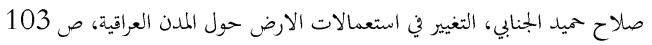

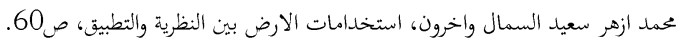

$$
\begin{aligned}
& \text { قطاع الرعاية الصحية في البغدادي، بيانات غير منشورة لعام } 2019 \\
& \text { الدراسة الميدانية }
\end{aligned}
$$

